Rev. Saúde públ., S. Paulo

$14: 88-92,1980$

\title{
REAÇÕES CLINICAS À VACINAÇÃO DE ADULTOS CONTRA A RUBÉOLA *
}

J. A. N. Candeias **

M. L. Rácz**

\begin{tabular}{l|l|}
\hline RSPUB9/489 \\
\hline
\end{tabular}

CANDEIAS, J. A. N. \& RÁcz, M. L. Reaşóes clínicas à vacinação de adultos contra a rubéola. Rev. Saúde públ., S. Paulo, 14:88-92, 1980.

RESUMO: Descreve-se a incidencia comparativa $e$ as caracteristicas das reações associadas à vacinaçáo contra a rubéola de 305 mulheres adultas na faixa etária de 20 a 35 anos ou mais, com a vacina $R A$ 27/3: 238 vacinaçóes $(77,8 \%)$ sem qualquer reação; 6 casos $(1,9 \%)$ com febre, artralgias e adenopatia retro-auricular; 8 casos $(2,6 \%)$ com os mesmos sintomas anteriores $e$ "rash" rubeliforme; 21 casos (6,9\%) com adenopatia retro-auricular; mal estar geral sem sintomas respiratórios, 25 casos $(8,2 \%)$ e com sintomas respiratórios das vias superiores, 8 casos $(2,6)$.

UNITERMS: Rubéola, vacina.

INTRODUGAO

As vacinas atenuadas que se utilizam na profilaxia da rubéola desencadeiam, de um modo geral, una resposta imunitária satisfatória $2 . \overline{7}, 11,17$. Alguns autores referem a ocorrência de reações pós-vacinais, cuja intensidade parece estar relacionada com o tipo de vacina, com a idade e sexo dos vacinados 1,5,16,19,21. Em trabalho anterior ${ }^{3}$ não pudemos notar qualquer reação nos indivíduos vacinados, no entanto, consideramos que esta observação poderia resultar do número limitado de casos em estudo, razão pela qual se iniciou uma pesquisa mais ampla, com o objetivo de descrever a incidência comparativa $e$ as caracteristicas de reações eventualmente associadas à vacinação contra a rubéola.

\section{MATERIAL E METODOS}

\section{Individuos Vacinados}

Os indivíduos selecionados para vacinação provieram de um total de 8.582 professoras da rede municipal de ensino de São Paulo, cujos soros foram testados qualitativamente para determinação do grau de imunidade contra rubéola, através da reação de inibição da hemaglutinação. Foram vacinadas 600 mulheres, com idade entre 20 e 35 anos ou mais, em que foi confirmada a ausência de imunidade contra rubéola.

\section{Vacina}

Foi utilizada a vacina RA $27 / 3$, em dose única de $0,5 \mathrm{ml}$, administrada por via subcutânea, na região deltóide.

\footnotetext{
* Pesquisa financiada pelo Departamento de Assistência Escolar da Secretaria de Educação da Prefeitura Municipal de $\mathbf{S}$. Paulo.

** Do Departamento de Microbiologia e Imunologia do Instituto de Ciências Biomédicas da USP, "Setor Saúde Pública" - Av, Dr. Arnaldo, 715 - 01255 - S. Paulo, SP, Brasil.
} 
CANDEIAS, J. A. N. \& RACZ, M. L. Reações clínicas à vacinação de adultos contra a rubéolà. Rev. Saúde públ., S. Paulo, $14: 88-92,1980$.

No momento da vacinação, as mulheres eram esclarecidas sobre as possiveis reaçōes à vacina e convocadas a comparecer após 10 dias para relatar as reaçōes ocorridas.

\section{RESULTADOS}

Das 600 mulheres vacinadas, somente 306 $(51,0 \%)$ atenderam à convocação 10 dias após a vacinação. $\mathrm{Na}$ Tabela descriminamse os resultados obtidos.

Pode-se observar que $77,8 \%$ das vacinadas não referiram quaisquer sintomas, 10 dias após a vacinação, enquanto $22,2 \%$ referiram um ou mais sintomas, no mesmo período de tempo. Dos 14 casos $(4,5 \%)$ com sintomas associados, isto é, febre, artralgias e adenopatia retro-auricular, com ou sem "rash" cutâneo, 9 descreveram os sintomas articulares como localizados ao nivel das articulaçōes dos dedos e os $\mathbf{5}$ restantes ao nivel do pulso e do tornozelo. A informação de mal-estar geral, com ou sem sintomas respiratórios, foi dada pela maior percentagem das mulheres vacinadas $(10,8 \%)$, seguindo-se a ocorrência de gânglios retro-auriculares, sem outros sintomas $(6,9 \%)$, e as queixas de sintomas associados $(4,5 \%)$.

T A B E L A

Reações à vacinação de adultos com a vacina RA27/3

\begin{tabular}{|c|c|c|c|c|c|c|c|c|c|c|c|c|c|}
\hline \multirow{3}{*}{\multicolumn{2}{|c|}{$\begin{array}{c}\text { Sem } \\
\text { sintomas } \\
\text { pós-vacinais }\end{array}$}} & \multicolumn{10}{|c|}{ Com sintomas pós-vacinais } & & \\
\hline & & \multicolumn{4}{|c|}{ Associados } & \multirow{2}{*}{\multicolumn{2}{|c|}{$\begin{array}{l}\text { Gânglios } \\
\text { retro-auri- } \\
\text { culares }\end{array}$}} & \multicolumn{4}{|c|}{ Mal-estar geral } & \multirow{2}{*}{\multicolumn{2}{|c|}{ Total }} \\
\hline & & \multicolumn{2}{|c|}{$\begin{array}{l}\text { sem } \\
\text { "rash" }\end{array}$} & \multicolumn{2}{|c|}{$\begin{array}{l}\text { com } \\
\text { "rash" }\end{array}$} & & & \multicolumn{2}{|c|}{$\begin{array}{l}\text { sem sintomas } \\
\text { respiratórios }\end{array}$} & \multicolumn{2}{|c|}{$\begin{array}{l}\text { rom sintomas } \\
\text { respiratórios }\end{array}$} & & \\
\hline No & $\%$ & No & $\%$ & No & $\%$ & $\mathrm{~N}_{\mathrm{O}}$ & $\%$ & $\mathrm{~N}^{\circ}$ & $\%$ & No & $\%$ & No & $\%$ \\
\hline \multirow[t]{2}{*}{238} & 77,8 & 6 & 1,9 & 8 & 2,6 & 21 & 6,9 & 25 & 8,2 & 8 & 2,6 & 306 & 100 \\
\hline & & & & & & & & & & & + & & \\
\hline
\end{tabular}

\section{DISCUSSÃ E CONCLUSAO}

$O$ quadro de rubéola em adultos é, freqüentemente, complicado com sintomas de artrite, sintomas musculares e parestesias, complicações estas que podem ser observadas após a vacinação com os diversos tipos de vacina atenuada usados na profilaxia da rubéola $4,8,10,13$. A artralgia pós-vacinal é mais freqüente em adultos do que em crianças, o que poderia, eventualmente, estar relacionado com fenômenos de hipersensibilidade, em individuos anteriormente sensibilizados pelo virus da rubéola. Black e col. ${ }^{1}$ demonstraram ser esta explicação infundada, ao estudarem as reações à vacinação contra a rubéola de membros de populações índias da região Anıazônica. Independentemente de uma possível explicação para a frequiência das reações artríticas pós-vacinais, sua ocorrência parece ser uma constante, ao contrário do que sucede com outras complicações como "rash" cutâneo, linfadenopatia, sintomas respiratórios e parestesias ${ }^{1,4}$. Os resultados por nós obtidos confirmam a ocorrência de artralgias, muito embora sua freqüência tenha sido menor $(4,5 \%)$, do que a de outros sintomas, particularmente, mal-estar geral, com ou sem sintomas respiratórios $(10,8 \%)$, e presença de gânglios retro-auriculares $(6,9 \%)$. Quando nos referimos aos sintomas articulares, baseamo-nos, exclusivamente, nas queixas refe- 
CANDEIAS, J. A. N. \& RACZ, M. L. Reações clínicas à vacinação de adultos contra a rubéola. Rev. Saúde puibl., S. Paulo, 14:88-92, 1980.

ridas pelas mulheres vacinadas no que respeita a dores articulares. Não houve preocupação, nem possibilidade de caracterizar em que extensão tais queixas correspondiam a quadros de artrite ou a simples artralgias, notando-se, no entanto, que esta sintomatologia apresentava caráter transitório, mantendo-se por 2 a 3 dias, ou, em alguns casos, 7 dias, tal como já tinha sido observado por outros autores 6,7,20,21. Estas complicações, poderão, no entanto, progredir para um quadro crônico de artrite reumatóide 14,15.

Um dos problemas cuja solução nem sempre se mostra adequada, em estudos da natureza do que apresentamos, diz respeito ao modo de obter as informações sobre as possiveis complicações vacinais, e ao momento em que tais informações devem ser coletadas. Experiência havida anteriormente 3 e confirmada no presente estudo, em que só foi possivel examinar $51,0 \%$ das mulheres vacinadas, levou-nos a solicitar o retorno ao fim de 10 dias após a vacinação, momento em que nos pareceu estarem as vacinadas ainda condicionadas para atender a nosso pedido. Por outro lado, dada a natureza do grupo em estudo, consideramos mais adequado fornecer às mulheres vacinadas uma relação de alguns dos possiveis sintomas pós-vacinais, especificamente, aparecimento de gânglios retro-auriculares, possivel inchaço das articulaçōes, acompanhado ou não de dor e aparecimento de manchas avermelhadas no corpo, esperando que outros sintomas viessem a ser referidos. A utilização de questionários e a entrevista pessoal ou por telefone, frequentemente utilizados para coletar dados sobre as reações à vacinação, passados periodos mais longos de tempo ${ }^{5,10}$, fornecem, certamente, dados mais precisos e, possivelmente, não enviesados, no entanto, não foi considerada viável sua aplicação no estudo presente. $O$ periodo de 10 dias utilizado não se afasta muito das duas semanas consideradas como o momento em que os sintomas pós-vacinais se tornam mais freqüientes.

Considerados numa perspectiva global, nossos resultados com $22,2 \%$ de reações vacinais, das quais somente $4,5 \%$ correspondem a sintomas articulares associados ou não à presença de adenopatia retro-auricular, "rash" e febre, caracterizam uma observação que se afasta, de modo muito acentuado de alguns dados referidos pela literatura, que citam a ausência de diferenças entre a vacina RA $27 / 3$ e as demais vacinas utilizadas, HPV77DE5 e Cendehill, no que respeita às reações vacinais $\mathrm{e}$, no grupo etário de 26 a 41 anos, acusam um percentual da ordem de $60 \%$ das mulheres vacinadas com queixas articulares ${ }^{12}$. Apesar de nossas observaçōes poderem estar sujeitas a crítica, pelo método utilizado no levantamento das queixas apresentadas depois da vacinação, por certo, com um ponderável contingente de subjetividade difícil de controlar e pelo curto espaço de tempo que medeia entre a vacinação e aquele levantamento, parecem-nos de certo interesse, por refletirem uma experiência com o uso da vacina RA $27 / 3$, que induz uma resposta imunitária qualitativa e quantitativamente semelhante à infecção natural $18 \mathrm{e}$ que melhor parece atender aos requisitos minimos de uma vacina contra a rubéola 9,16. 
CANDEIAS, J. A. N. \& RÀCZ. M. L. Reações clínicas à vacinação de adultos contra a rubéola. Rev. Saíde públ., S. Paulo, 14:88-92. 1980.

RSPUB $9 / 489$

CANDEIAS, J. A. N. \& RÁCZ, M. L. CClinical reactions against rubella vaccine in adults.] Rev. Saúde públ., S. Paulo, 14:88-92, 1980.

ABSTRACT: A study of rubella vaccine associated reactions in 306 women, aged 20 to 35 or more, following RA $27 / 3$ vaccination is presented. In 238 of the vaccinated women (77.8\%) no symptoms or signs were noted; fever, arthralgia, and lymphadenopathy were noticed in 6 cases $(1.9 \%)$; eight cases $(2.6 \%)$ developed fever, arthralgia, lymphadenopathy, and rubelliform rash; 21 cases $(6.9 \%)$ developed lymphadenopathy; malaise without respiratory symptoms were noticed in 25 cases $(8.2 \%)$ and mild respiratory symptoms in 8 cases $(2.6 \%)$.

UNITERMS: Rubella, vaccine.

\section{REFERENCIAS BIBLIOGRÁFICAS}

1. BLACK. F. et al. Reaction to rubella vaccine and persistence of antibody in virgin-soil population after vaccination and wild virus induced immunization. J. infect. Dis., 133:393-8, 1976.

2. BOLOGNESE, R. J. \& CORSON, S. L Rubella vaccination: a critical review. Obstet, and Gynec., 42:851-5. 1973.

3. CANDEIAS, J. A. N. et al. Resposta soro. lógica de adultos à vacinação contra a rubéola. Rev. Saúde públ., S. Paulo, $11: 345-52,1977$.

4. COOPER, L. $z$. et al. Transient artritis after rubella vaccination. Amer. $J$. Dis. Child., 118:218-25, 1969.

5. DUDGEON, J. A. et al. Clinical and laboratory studies with rubella raccines in adults. Brit, med. J., 1:271-6, 1968.

6. DUDGEON, J. A. et al. Rubella vaccine trials in adults and children. Amer. $J$. Dis. Child., 118:237-42, 1969.

7. FOX. J. $P$. et al. Rubella vaccine in pospubertal. women experience in western Washington State. J. Amer. med. Ass., 236:837-43, 1976.

8. FRY, J, et al. Rubella, Brit. ned. J., 2: $833-4,1962$.

9. GITNICK. G. L. et al. Progress in rubella vaccine development: review and studies of growth of rubella in chick embryo tissue culture. Amer. $J$. publ. Hlth, 58:1237-47, 1969.
10. GRAND, M. G. et al. Clinical reactions following rubella vaccination. A prospective analysis of joint, muscular and neuritic symptoms. J. Amer, med. Ass. $220: 1569-72,1972$.

11. HERRMANN, K, L. Rubella immunization: persistence of antibody four years after a large-scale field trial. J. $A m \bullet r$. med. Ass., 235:2201-4, 1976.

12. HORSTMANN, D. M. Problems in measies and rubella. $D M, 24: 28-52,1978$.

13. LEHANE, D. E, et al. Evaluation of rubella herd immunity during an epidemic. J. Amer. med. Ass, $213: 2236-40$, 1970.

14. MARTENIS, T. W. et al. Rheumatoid arthritis after rubella. Arthr. and Rheum., 11:683-5, 1968.

15. OGRA, P. L. \& HERD, J. K. Arthritis associated with induced rubella infection. J. Immunol, 107:810-3, 1971.

16. PLOTKIN, S. A, et al. Attenuation of RA $27 / 3$ rubella virus in WI-38 human diploide cells. Amer, J. Dis. Child., $118: 178-85,1969$

17. PLOTKIN, S. A. et al. Immunologic properties of RA $27 / 3$ rubella virus vaccine: a comparison with strains pre- 
CANDEIAS, J. A. N. \& RÀCZ, M. L. Reações clinicas à vacinação de adultos contra a rubéola. Rev. Saúde públ., S. Paulo, 14:88-92, 1980.

sently licensed in United States. $J$. Amer. med. Ass., 225:585-90, 1973.

18. RHODES, A. J. et al. Rubella virus infection diagnosis: present status. In: Kurstak, E. \& Kurstak, C., eds. Comparative diagnosis of viral diseases. New York, Academic Press. 1977. v. 1., p. 748 .

19. SCHIFF, G. M. et al. Evaluation of RA $27 / 3$ rubella vaccine. $J$. Pediat., 85: $379-81,1974$.
20. SPRUANCE, S. P. \& SMITH. C. B. Joint complications associated with derivations of HPV -77 rubella virus vaccine. Amer. J. Dis. Child., 122:105-11, 1971.

21. WALLACE. R. B. et al. Joint symptoms following an area-wide rubella immunization campaign. Report of a survey. Amer. J. publ. Hith, 62:658-61. 1972.

Recebido para publicacão em 31/08/1979 Aprovado para publicaşáo em 30/10:1979 